\title{
A Psychometric Analysis of Fear of COVID-19 Scale in India
}

\author{
Remya Lathabhavan ${ }^{1}$ (D)
}

Accepted: 14 September 2021 / Published online: 4 October 2021

(c) The Author(s), under exclusive licence to Springer Science+Business Media, LLC, part of Springer Nature 2021

\begin{abstract}
COVID-19 has had a serious negative impact on the mental health of people around the world. The present study analyses the psychometric properties of Fear of COVID-19 Scale (FCV-19S) in the Indian context. The study checks the one-factor and two-factor structures of the measure. Data were collected from 992 respondents from India. Structural equation modeling was performed to check the construct validity after checking the factorial validity, reliability, and model fit. Both one-factor and two-factor models had good psychometric properties. FCV-19S had significant relationships with stress and wellbeing. This study can serve as a reference to practitioners and researchers to understand and analyze fear of COVID among individuals and thus to support the mental health wellbeing during the pandemic.
\end{abstract}

Keywords COVID-19 $\cdot$ Mental health $\cdot$ Fear of COVID-19 $\cdot$ Psychometric analysis

The rapid transmission and high mortality rates of the novel coronavirus pandemic (COVID-19) has elicited worldwide fear in the past year (Bitan et al., 2020). Pandemicrelated fear and anxiety have severely affected the mental health of people around the globe (Rajkumar, 2020). The Fear of COVID-19 Scale (FCV-19S) has recently been developed to quantify and qualify the mental health aspects of such anxiety (Ahorsu et al., 2020). The scale has been validated in several geographic areas to ascertain its general adaptability (Bitan et al., 2020; Satici et al., 2020a).

The present study analyzes the adoption of FCV-19S in the Indian context. This study is important given the large population of India and the severity of the pandemic in the country (Ghosh et al., 2020; Roy et al., 2020). The impacts of COVID-19 on the Indian population have been severe. From the societal perspective, the economically disadvantaged people have been worst hit due to pandemic restrictions as most of them earn daily wages in the agricultural and other unorganized sectors (Ghosh et al., 2020). The pandemic has thus exacerbated poverty and socio-economic inequalities in the country, which has led to fear and insecurities of existence (Gopalan \& Misra, 2020). Factors other than the financial burden of the pandemic, have raised the stress levels of the people of India. The cultural background (e.g., association of the disease with

Remya Lathabhavan

remya.1@vit.ac.in

1 Department of Technology Management, VIT University, Vellore, India 
a divine plan) and stigma associated with the pandemic have instigated anxiety among the people (Chandra et al., 2020). In some cases, politicization of the pandemic situations has increased stigma and promoted stereotypes. The restrictions posed by governments, while undoubtedly necessary from the standpoint of pandemic containment, have increased fear and anxiety among people (Bhanot et al., 2021; Mahajan \& Kaushal, 2020; Siddiqui et al., 2020). There is also latent worry of self or loved ones catching the infection (Lathabhavan \& Vispute, 2021). Finally, information (and often misinformation) and news in both mainstream and social media also aggravate the fear (Abdullah, 2020; Scopelliti et al., 2021). Although useful data on the status of the pandemic are indeed provided by the media, the sensational nature of the data or reporting method can induce panic and fear (Roy et al., 2020; Venkatesh \& Gandhi, 2020).

Given the rampant pandemic-related fear and anxiety in the country, the current study validates the Fear of COVID-19 Scale (FCV-19S) in the Indian context. FCV-19S was developed to analyze the fear of individuals towards the disease and thus to understand the mental health implications (Ahorsu et al., 2020). The present study evaluates the two-factor structure of the scale. The specific objectives of the study are three-fold:

First, the study aims to evaluate the factorial validity of the scale, in which both onefactor and two-factor structures are compared.

Second, the study aims to evaluate the internal validity of scale in the Indian environment, for which Cronbach's alpha values are considered.

Third, the study checks the construct validity of the scale with two validating variables, viz., perceived stress and wellbeing for both one-factor and two-factor structures.

\section{Methods}

\section{Participants and Procedures}

This study was conducted during COVID-19 pandemic outbreak in India during July 2020. Data were collected from 992 participants in India. An online survey was conducted, adhering to the pandemic preventive measures. Residents of six states - Mahrashtra, Tami Nadu, Karanataka, Kerala, Andra Pradesh, and Delhi — whose mother tongue was Hindi, were chosen for this study. These states were selected because of the high infection rates during the time specified. Among 992 respondents, 562 were men and 430 were women. The mean age of respondents was 37.8 years.

The participants were selected using an online survey, and a snowball sampling strategy was followed. The survey details containing a brief description of the study and a Google Forms link were shared via famous social media websites, Twitter and Facebook, and also to personal email address. The survey was administered online to comply with lockdown restrictions and to ensure wide reach and access. The participants were requested to share the survey with their colleagues.

Participants were asked to provide demographic information and measures including FCV-19S. Demographic information were optional to fill, whereas all other items relating to constructs were mandatory. Participation was voluntary. All participants were required to provide informed consent in electronic form and received no compensation for their participation. 


\section{Measures}

The Fear of COVID-19 Scale was measured using a 7-items scale developed by Ahorsu et al. (2020). The 7-items assessed the fear of respondents about the pandemic situation. A seven-point Likert-type scale was used with anchors 1 (strongly disagree) to 7 (strongly agree). Sample items are "I am most afraid of Corona" and "My heart races or palpitates when I think about getting Corona." The Cronbach's alpha was 0.82 for this study. The scale was translated into Hindi, the largest spoken language in India, and then translated back to English and compared by two English professors and one native English speaker.

Perceived stress: The shorter version of Perceived Stress Scale (Cohen et al., 1983) was used for this study. A sample item is "In the last month how often have you felt you were unable to control the important things in your life?". A seven-point Likert-type scale was used with anchors 1 (strongly disagree) to 7 (strongly agree). The Hindi version of scale exhibited good reliability $(\alpha=0.89)$.

Wellbeing was measured using WHO-Five Well-being Index (WHO-5). A sample item is "I have felt calm and relaxed." A seven-point Likert-type scale was used with anchors 1 (strongly disagree) to 7 (strongly agree). The Cronbach's alpha of the translated Hindi version was 0.85 for this study.

\section{Statistical Analysis}

Structural equation modeling methods were implemented in AMOS 25.0 (Arbuckle, 2016) and used for analysis. The factorial validity of the one-factor model and twofactor model structures were tested first and then the research model was validated using the fit version of FCV-19S. Confirmatory factor analysis was performed with maximum likelihood estimation to examine the suitability of the one-factor and two-factor models. The goodness-of-fit values of the models were evaluated using the following criteria on goodness-of-fit indices: the goodness-of-fit index $(\mathrm{GFI}) \geqslant 0.80$, adjusted goodness of fit index $(\mathrm{AGFI}) \geqslant 0.80$, the comparative fit index $(\mathrm{CFI}) \geqslant 0.90$, Tucker-Lewis index $(T L I) \geqslant 0.90$, the root mean square error of approximation (RMSEA) $\leqslant 0.08$, and the standardized root mean square residual $(\mathrm{SRMR}) \leqslant 0.06$ (Hu \& Bentler, 1998). To assess the reliability of the FCV-19S, Cronbach's $\alpha$ coefficients - indicators of internal consistency and homogeneity - were analyzed. Cronbach's $\alpha$ coefficients of 0.70 or higher were adopted as the cutoff criteria (Nunnally, 1994).

\section{Results}

\section{Factorial Validity of FCV-19S in India}

The exploratory factor analysis showed that the single factor structure of COVID-19 scale had a variance of $53.02 \%$. For exploring the potential structure, two-factor structure was checked using varimax rotation. The two-factor structure accounted for $64.75 \%$ variance. Items 1, 2, 4, and 5 were highly correlated and represented the affective response of fear. The second factor in which items 3, 6, and 7 were highly correlated represented physiological response. A comparison of one-factor and two-factor structure is presented in Table 1. 
Table 1 Comparison of one-factor and two-factor structures of FCV-19S in India

\begin{tabular}{|c|c|c|c|c|}
\hline & \multirow[t]{2}{*}{ Items } & \multirow{2}{*}{$\begin{array}{l}\text { Corrected item- } \\
\text { total correlation }\end{array}$} & \multicolumn{2}{|l|}{ Factors } \\
\hline & & & $\begin{array}{l}\text { physi- } \\
\text { ological } \\
\text { response }\end{array}$ & $\begin{array}{l}\text { Affective } \\
\text { response }\end{array}$ \\
\hline 1 & I am most afraid of COVID-19 & .638 & & .835 \\
\hline 2 & It makes me uncomfortable to think about COVID-19 & .600 & & .741 \\
\hline 3 & My hands become clammy when I think about COVID-19 & .746 & .810 & \\
\hline 4 & I am afraid of losing my life because of COVID-19 & .683 & & .707 \\
\hline 5 & $\begin{array}{l}\text { When watching news and stories about COVID-19 on } \\
\text { social media, I become nervous or anxious }\end{array}$ & .569 & & .753 \\
\hline 6 & $\begin{array}{l}\text { I cannot sleep because I'm worrying about getting COVID- } \\
19\end{array}$ & .721 & .892 & \\
\hline 7 & $\begin{array}{l}\text { My heart races or palpitates when I think about getting } \\
\text { COVID-19 }\end{array}$ & .809 & .833 & \\
\hline
\end{tabular}

$N=992$

Table 2 Results of confirmatory factor analysis of FCV-19S in India

\begin{tabular}{llllllllll}
\hline Scale & $\chi 2$ & $d f$ & $p$ & GFI & AGFI & CFI & TLI & RMSEA & SRMR \\
\hline $\begin{array}{l}\text { FCV-19S } \\
\begin{array}{l}\text { 1-factor } \\
\text { FCV-19S }\end{array}\end{array}$ & 22.30 & 14 & $<0.01$ & .93 & .87 & .94 & .91 & .10 & .05 \\
$\begin{array}{l}\text { 2-factor } \\
\text { farto }\end{array}$ & 13 & $<0.01$ & .95 & .89 & .96 & .95 & .07 & .04 \\
\hline
\end{tabular}

$n=992$, chi-square from maximum likelihood robust estimation; $d f$ degrees of freedom, $G F I$ goodness of fit index, AGFI adjusted goodness-of-fit index, CFI comparative fit index, TLI Tucker-Lewis index, RMSEA root mean square error of approximation, SRMR standardized root mean square residual

Table 3 Means and standard deviations of FCV-19S (India)

\begin{tabular}{llrr}
\hline & Items & Mean & $S D$ \\
\hline 1 & I am most afraid of COVID-19 & 4.04 & 1.06 \\
2 & It makes me uncomfortable to think about COVID-19 & 0.74 \\
3 & My hands become clammy when I think about COVID-19 & 3.40 & 0.92 \\
4 & I am afraid of losing my life because of COVID-19 & 2.30 & 1.02 \\
5 & When watching news and stories about COVID-19 on social media, I & 3.18 & 0.88 \\
& $\quad$ become nervous or anxious & 1.70 & 0.71 \\
7 & I cannot sleep because I'm worrying about getting COVID-19 & 2.07 & 1.10 \\
& My heart races or palpitates when I think about getting COVID-19 & 19.63 & \\
\hline
\end{tabular}


The confirmatory factor analyses of the one-factor and two-factor structure are shown in Table 2. The two-factor model showed better fit compared to the one-factor structure.

\section{Descriptive Statistics of FCV-19S}

Table 3 shows the descriptive statistics of FCV-19S. The mean scores (standard deviations) of the Indian scale ranged between 1.70 and $4.04(0.71-0.10)$ for different items of the FCV-19S in the given study. This agrees with results from other studies in this area. For FCV-19S in Israeli population, the mean scores ranged between 1.56 and 3.23 and standard deviation ranged between 0.73 and 1.15 (Bitan et al., 2020). Likewise, for Iranian sample, the scores of mean and standard deviation were 3.48-4.26, and 0.75-1.14, respectively (Reznik et al., 2020). For Russia and Belarus samples, the mean ranged between 1.53 and 3.31 and standard deviation between 0.66 and 1.14 (Reznik et al., 2020).

All the Cronbach's alphas were higher than 0.70 ( 0.85 for one-factor structure, 0.82 for affective response, and 0.86 for physiological response).

\section{Relationship with Other Variables}

To investigate the relationship with other variables, perceived stress and wellbeing were considered for the study. Table 4 shows the relationships among the variables. As expected, fear of COVID-19 had a positive relationship with perceived stress and negative relationship with wellbeing.

\section{Discussion}

The study aimed to assess the psychometric properties of the FCV-19S among Indian population. The current study revealed the existence of a two-factor structure of the FCV19S, viz., affective response and physiological response. The paper checked the factorial validity, reliability, and construct validity of both one-factor and two-factor structure of FCV-19S.

Both one-factor and two-factor structures showed good psychometric properties. It was found that the two-factor structure had a better fit for the model with $\chi^{2}$ statistics, RMSEA and SRMR, and also the highest values for GFI, AGFI, CFI, and TLI. This agrees with the results of previous validation studies on two-factor models of FCV-19S (Andrade et al.,

Table 4 Correlation between FCV-19S and validating variables

\begin{tabular}{llllll}
\hline & 1 & 2 & 3 & 4 & 5 \\
\hline $\begin{array}{l}\text { 1. Fear of COVID-19 } \\
\text { 2. Affective response }\end{array}$ & .85 & & & & \\
(factor 1) & $.93^{* * *}$ & .82 & & & \\
$\begin{array}{l}\text { 3. Physiological } \\
\text { response (factor 2) }\end{array}$ & $.89 * *$ & $.64 * * *$ & .86 & & \\
$\begin{array}{l}\text { 4. Perceived stress } \\
\text { 5. Wellbeing }\end{array}$ & $.25 *$ & $.23 * * *$ & $.25 * * *$ & .89 & \\
\hline
\end{tabular}

$N=992, * p<0.05, * * * p<0.001$. Cronbach's $\alpha$ on diagonal 
2020; Bitan et al., 2020; Reznik et al., 2020). For FCV-19S, acceptable internal consistencies were found for the three factors $(\alpha>0.70)$. Overall, the study provides evidence that support the two-dimensional validity of the scale.

It was also found that fear of COVID-19 significantly associated with validating variables. It had a positive relationship with perceived stress and negative relationship with wellbeing. These findings are also consistent with previous studies (Pakpour et al., 2020; Satici et al., 2020b; Soares et al., 2021). Thus the study provides a potential contribution to Fear of COVID literature by analyzing the psychometric properties of FCV-19S in India.

Another interesting contribution of the current study is that its results agree with the outcomes of newly developed, pandemic-related scales especially for understanding and handling the mental health concerns. The results of the study show similarity with results of Fear of Corona Virus, that was developed last year (Mertens et al., 2020). The findings of this study are also consistent with the results in the study of COVID stress scale where fear as factor (Taylor et al., 2020).

The practical implications of this study are multifold. First, by analyzing the nature of fear, it will be easier to diagnose and treat mental health issues of people. As the level and characteristics of fear vary among people and situations, a comprehensive understanding will help practitioners provide appropriate interventions (Freeman et al., 2018; Geller et al., 2016).

Second, the study can assist the government and community organizations to design fear reduction interventions and mitigation strategies. Governments can ensure accessibility of professionals who can advise the public and disseminate correct information and debunk fake news (Harper et al., 2020; Ornell et al., 2020). As a fear mitigation measure, governments can provide training on stress management to citizens and implement technological supports such as tele-counseling and tele-medicine (Ornell et al., 2020; Zhou et al., 2020).

Third, the study helps in understanding the severity of fear of COVID-19 on mental health of individuals, and hence practitioners and policy makers can frame better management strategies. Techniques such as implementation of tele-psychiatry, assigned task for mental health and innovative methods adopted for dissemination of COVID-19 etc. adopted by the Arab countries in the MENA region may be adopted by other countries with region specific modifications and improvements (El Hayek et al., 2020). Fourth, news media outlets that have considerable influence on people during times of crisis can work on mitigating strategies such as avoiding fake news and providing news that enhance hope and positivity (Abdullah, 2020; Scopelliti et al., 2021).

Finally, this study would help in adoption of the scale in different sectors and levels of society in order to understand fear component among different demographics.

One limitation of this study is that it used cross-sectional data that was self-reporting nature. Future studies can concentrate on longitudinal studies in order to obtain the general nature of psychological aspects. Studies with larger sample sizes and specific sectors would also provide a comprehensive understanding on the validity of the scale.

\section{Conclusion}

The current study supports both one-factor and two-factor models of FCV-19S as appropriate versions in the Indian context. Through this validation, this study provides deeper understanding on the usage of the scale and thus increases the avenues for research for researchers and practitioners. Future research in this area would help in improvements in the mental health outcomes of the pandemic. 
Acknowledgement None.

Funding No funding received.

Data Availability The data available on request.

\section{Declarations}

Human and Animal Rights Not applicable.

Informed Consent Not applicable.

\section{Conflict of Interest None.}

Ethical Approval The research confined to the highest level of ethics. All procedures performed in this study involving human participation are conducted accord-ing to the ethical standards of 1975 Helsinki Declaration.

\section{References}

Abdullah, I. (2020). COVID-19: Threat and fear in Indonesia. Psychological Trauma: Theory, Research, Practice, and Policy, 12(5), 488-490.

Ahorsu, D. K., Lin, C. Y., Imani, V., Saffari, M., Griffiths, M. D., \& Pakpour, A. H. (2020). The fear of COVID-19 scale: Development and initial validation. International Journal of Mental Health and Addiction. https://doi.org/10.1007/s11469-020-00270-8

Andrade, E. F., Pereira, L. J., Oliveira, A. P. L. de, Orlando, D. R., Alves, D. A. G., Guilarducci, J. de S., \& Castelo, P. M. (2020). Perceived fear of COVID-19 infection according to sex, age and occupational risk using the Brazilian version of the fear of COVID-19 scale. Death Studies, O(0), 1-10. https://doi. org/10.1080/07481187.2020.1809786

Arbuckle, J. L. (2016). IBM® SPSS® User's guide $\operatorname{Amos}^{\mathrm{TM}} 24$. IBM, Chicago, IL., 1-720. Accessed on 20.07.2020 ftp://public.dhe.ibm.com.

Bhanot, D., Singh, T., Verma, S. K., \& Sharad, S. (2021). Stigma and discrimination during COVID-19 pandemic. Frontiers in Psychology, 8(January), 1-11. https://doi.org/10.3389/fpubh.2020.577018.

Bitan, D. T., Grossman-Giron, A., Bloch, Y., Mayer, Y., Shiffman, N., \& Mendlovic, S. (2020). Fear of COVID-19 scale: Psychometric characteristics, reliability and validity in the Israeli population. Psychiatry Research, 289, 113100.

Chandra, P. S., Shiva, L., Nagendrappa, S., Ganjekar, S., \& Thippeswamy, H. (2020). COVID-19 related psychosis as an interface of fears, socio-cultural issues and vulnerability- case. Psychiatry Research, 290(May), 113136. https://doi.org/10.1016/j.psychres.2020.113136.

Cohen, S., Kamarck, T., \& Mermelstein, R. (1983). A global measure of perceived stress. Journal of Health and Social Behavior, 24(4), 385-396.

El Hayek, S., Cheaito, M. A., Nofal, M., Abdelrahman, D., Adra, A., Al Shamli, S., AlHarthi, M., AlNuaimi, N., Aroui, C., Bensid, L., Emberish, A. M., Larnaout, A., Radwan, A., Slaih, M., \& Al Sinawi, H. (2020). Geriatric mental health and COVID-19: An eye-opener to the situation of the Arab countries in the Middle East and North Africa region. American Journal of Geriatric Psychiatry, 28(10), 1058-1069. https://doi.org/10.1016/j.jagp.2020.05.009.

Freeman, D., Haselton, P., Freeman, J., Spanlang, B., Kishore, S., Albery, E., Denne, M., Brown, P., Slater, M., \& Nickless, A. (2018). Automated psychological therapy using immersive virtual reality for treatment of fear of heights: A single-blind, parallel-group, randomised controlled trial. The Lancet Psychiatry, 5(8), 625-632. https://doi.org/10.1016/S2215-0366(18)30226-8.

Geller, D. A., McGuire, J. F., Orr, S. P., Small, B. J., Murphy, T. K., Trainor, K., Rachel, \& Porth, Sabine Wilhelm, E. A. S. (2016). Fear extinction learning as a predictor of response to cognitive behavioral therapy for pediatric obsessive compulsive disorder. Physiology \& Behavior, 176(1), 139-148. https:// doi.org/10.1016/j.janxdis.2019.02.005.Fear.

Ghosh, A., Nundy, S., \& Mallick, T. K. (2020). How India is dealing with COVID-19 pandemic. Sensors International, 1(July), 100021. https://doi.org/10.1016/j.sintl.2020.100021. 
Gopalan, H. S., \& Misra, A. (2020). Diabetes \& metabolic syndrome: Clinical research \& reviews COVID19 pandemic and challenges for socio-economic issues, healthcare and national health programs in India. Diabetes \& Metabolic Syndrome: Clinical Research \& Reviews, 14(5), 757-759. https://doi.org/ 10.1016/j.dsx.2020.05.041.

Harper, C. A., Satchell, L. P., Fido, D., \& Latzman, R. D. (2020). Functional fear predicts public health compliance in the COVID-19 pandemic. International Journal of Mental Health and Addiction. https://doi.org/10.15446/revfacmed.v68n1.86482.

Hu, L. T., \& Bentler, P. M. (1998). Fit indices in covariance structure modeling: Sensitivity to underparameterized model misspecification. Psychological Methods, 3(4), 424-453. https://doi.org/10.1037/ 1082-989X.3.4.424.

Lathabhavan, R., \& Vispute, S. (2021). Examining the mediating effects of stress on fear of COVID-19 and Well-being using structural equation modeling. International Journal of Mental Health and Addiction.

Mahajan, P., \& Kaushal, J. (2020). Epidemic trend of COVID-19 transmission in India during lockdown-1 phase. Journal of Community Health, 45(6), 1291-1300. https://doi.org/10.1007/s10900-020-00863-3.

Mertens, G., Gerritsen, L., Duijndam, S., Salemink, E., \& Engelhard, I. M. (2020). Fear of the coronavirus (COVID-19): Predictors in an online study conducted in March 2020. Journal of Anxiety Disorders, 102258. https://doi.org/10.1016/j.janxdis.2020.102258.

Nunnally, J. C. (1994). Psychometric theory. Tata McGraw-hill education.

Ornell, F., Schuch, J. B., Sordi, A. O., \& Kessler, F. H. P. (2020). "Pandemic fear" and COVID-19: Mental health burden and strategies. Brazilian Journal of Psychiatry, 42(3), 232-235. https://doi.org/10.1590/ 1516-4446-2020-0008.

Pakpour, A. H., Griffiths, M. D., \& Lin, C. (2020). Assessing psychological response to the COVID-19: The fear of COVID-19 scale and the COVID stress scales. International Journal of Mental Health and Addiction.

Rajkumar, R. P. (2020). COVID-19 and mental health: A review of the existing literature. Asian Journal of Psychiatry, 52(January), 102066.

Reznik, A., Gritsenko, V., Konstantinov, V., Khamenka, N., \& Isralowitz, R. (2020). COVID-19 fear in Eastern Europe : Validation of the Fear of COVID-19 scale. International Journal of Mental Health and Addiction, 1-6.

Roy, D., Tripathy, S., Kumar, S., \& Sharma, N. (2020). Study of knowledge, attitude, anxiety \& perceived mental healthcare need in Indian population during COVID-19 pandemic. Asian Journal of Psychiatry, January.

Satici, B., Gocet-tekin, E., Deniz, M. E., \& Satici, S. A. (2020a). Adaptation of the fear of COVID-19 scale: Its association with psychological distress and life satisfaction in Turkey. International Journal of Mental Health and Addiction.

Satici, B., Saricali, M., Satici, S. A., \& Griffiths, M. D. (2020b). Intolerance of uncertainty and mental wellbeing: serial mediation by rumination and fear of COVID-19. International Journal of Mental Health and Addiction. https://doi.org/10.1007/s11469-020-00305-0.

Scopelliti, M., Pacilli, M. G., \& Aquino, A. (2021). TV news and COVID-19: Media influence on healthy behavior in public spaces. International Journal of Environmental Research and Public Health.

Siddiqui, A. F., Wiederkehr, M., Rozanova, L., \& Flahault, A. (2020). Situation of India in the COVID-19 pandemic: India's initial pandemic experience. International Journal of Environmental Research and Public Health.

Soares, F. R., Afonso, R. M., Martins, A. P., Pakpour, A. H., \& Rosa, C. P. (2021). The fear of the COVID19 Scale: Validation in the Portuguese general population. Death Studies.

Taylor, S., Landry, C. A., Paluszek, M. M., Fergus, T. A., Mckay, D., \& Asmundson, G. J. G. (2020). Development and initial validation of the COVID stress scales. Journal of Anxiety Disorders, 72(May), 102232. https://doi.org/10.1016/j.janxdis.2020.102232..

Venkatesh, U., \& Gandhi, P. A. (2020). Prediction of COVID-19 outbreaks using Google trends in India: A retrospective analysis. Healthcare Information Research, 26(3), 175-184.

Zhou, X., Snoswell, C. L., Harding, L. E., Bambling, M., Edirippulige, S., Bai, X., \& Smith, A. C. (2020). The role of telehealth in reducing the mental health burden from COVID-19. Telemedicine and E-Health, 26(4), 377-379. https://doi.org/10.1089/tmj.2020.0068.

Publisher's Note Springer Nature remains neutral with regard to jurisdictional claims in published maps and institutional affiliations. 